\title{
ORIGEN, MANTENIMIENTO Y EVOLUCIÓN DEL GINODIOICISMO
}

\author{
Eduardo Cuevas-García y César A. Abarca-Garcíaª \\ 'Departamento de Ecología de la Biodiversidad, Instituto de Ecología, Unidad Hermosillo, \\ Universidad Nacional Autónoma de México, Blvd. Luis Donaldo Colosio y Sahuaripa s/n, Apdo. \\ Postal 1354, C.P. 83000 Hermosillo, Sonora, México. \\ Correo-e: ecuevas@ecologia.unam.mx \\ ${ }^{2}$ Departamento de Ecología Evolutiva, Instituto de Ecología, Universidad Nacional Autónoma de \\ México, Apdo. Postal 70-275, Delegación Coyoacán, México 04510, D.F., México. \\ Correo-e: abarca_cesar@hotmail.com
}

\begin{abstract}
Resumen: Uno de los rasgos más característicos de las Angiospermas es la gran diversidad de sistemas reproductivos que presentan. Un ejemplo de ello es el ginodioicismo, caracterizado por la coexistencia de plantas hembra (estériles para la función masculina) y hermafroditas en la misma población. En este trabajo se presentan las principales características de las especies ginodioicas, tales como la gran variación de hembras que existe entre las poblaciones. Se explican las tres formas por las que se puede originar y transmitir la esterilidad masculina y sus consecuencias en la dinámica evolutiva. Asimismo, se presentan y discuten las hipótesis que explicarían la permanencia de las hembras en las poblaciones, ya que al carecer de la función masculina, necesitan producir más o mejores semillas para no estar en desventaja respecto a una hermafrodita. Se analizan las principales rutas evolutivas a partir de una condición hermafrodita y las evidencias actuales que sugieren que el ginodioicismo es la principal vía por la que se podría evolucionar a la dioecia. Finalmente, se hace una reflexión acerca del estado actual de la investigación de los sistemas reproductivos en México, poniendo para ello como ejemplo el estudio del ginodioicismo.
\end{abstract}

Palabras clave: Angiospermas, esterilidad masculina, sistema reproductivo.

Abstract: One of the main characteristics of Angiosperms is the great diversity of reproductive systems they present. Gynodioecy, namely the coexistence of hermaphrodite and female plants in the same population, is an example of such diversity. In this study we present the main characteristics of gynodioecious species, such as the large variation in female frequency among populations. We examine the three forms by which male sterility can be originated and transmitted, and their consequences for the evolutionary dynamics. We present and discuss the hypothesis that would explain the maintenance of females in populations, since due to the lack of male function, they need to produce more or better seeds than hermaphrodites to avoid a disadvantage. We analyze the main evolutionary routes beginning from a hermaphroditic condition, and the existing evidences that suggest gynodioecy as the main path in the evolution of dioecy. Finally, we analyze the present state of the investigation of reproductive systems in Mexico, using as an example the study of the gynodioecy.

Key words: Angiosperms, male sterility, reproductive system.

E el caso particular de las angiospermas, el hermafroditismo está considerado como la condición ancestral (Frohlich, 2003) a partir de la cual ha evolucionado el mayor repertorio de sistemas reproductivos que se conoce en la naturaleza. En el continuo de sistemas reproductivos podemos considerar en un extremo a las plantas hermafroditas, en las que las estructuras reproductivas masculinas y femeninas se encuentran en la misma flor, y las cuales representan entre $75 \%$ y $90 \%$ del total de las especies (Richards, 1986). En el otro extremo hallamos a las plantas dioicas, en las que las flores de un individuo son masculinas o femeninas, y las cuales representan entre $3.9 \%$ y $6 \%$ de las especies (Sakai y Weller, 1999). Entre estos dos extremos podemos encontrar prácticamente cualquier combinación en cuanto a las estructuras reproductivas se refiere; por ejemplo, poblaciones de plantas hermafroditas y de plantas masculinas (androdioicas; Pannell, 2002), poblaciones en donde los individuos presentan tanto flores hermafroditas como flores pistiladas (ginomonoicas; Collin y Shykoff, 2003), o poblaciones en las cuales hay individuos hermafroditas, hembras y machos (trioicas; Fleming et al., 1998), por mencionar algunos. Es 
decir, los sistemas reproductivos son entidades muy dinámicas que pueden sufrir modificaciones en escalas de tiempo ecológico y evolutivo (Barrett y Eckert, 1990). El estudio de la evolución de los sistemas reproductivos en las plantas nos ha ayudado a entender qué cambios han ocurrido en las características florales que intervienen directa o indirectamente en la reproducción, y posteriormente, qué repercusiones tienen estas características a nivel genético y ecológico en las especies (Sun, 1999; Schemske y Bradshaw, 1999). Uno de los objetivos principales del estudio de los sistemas reproductivos es intentar determinar el papel de las fuerzas evolutivas que están detrás de dichos cambios (Barrett y Eckert, 1990). Además, estos cambios pueden estar relacionados directa o indirectamente con el origen de nuevas especies, lo cual es un aspecto central de la teoría evolutiva (Darwin, 1859; Futuyma, 1998). En este artículo trataremos el origen, el mantenimiento y la posible transición de un sistema ginodioico para ilustrar el potencial que tiene el estudio de los sistemas reproductivos.

\section{El caso del ginodioicismo}

El ginodioicismo, definido como la coexistencia de plantas hembra y hermafroditas, ha evolucionado de manera independiente en al menos 71 familias y más de 500 especies, las que representan aproximadamente $0.6 \%$ del total de las angiospermas (Dem'yanova, 1985; Kaul, 1988). Al no producir polen, las plantas hembra deben forzosamente recibirlo de los hermafroditas, mientras que estos últimos pueden autofecundarse, y recibir polen de otras hermafroditas (Richards, 1986). Una de las características más notorias de las especies ginodioicas es la gran variación en la frecuencia de plantas hembra entre distintas poblaciones y/o especies (figura 1). Mientras que la mayoría de las especies tienen poblaciones hermafroditas, en otras la fre- cuencia de hembras puede ser tan alta como 98\% (Domme et al., 1978; cuadro 1). Además, es común observar que entre las flores pistiladas (o femeninas) la expresión fenotípica de la esterilidad masculina no es igual. Por lo tanto, en estas flores podemos observar desde órganos masculinos aparentemente bien desarrollados, sus reminiscencias (como filamentos cortos y/o anteras contraídas), o su ausencia total (cuadro 1). Otra característica sobresaliente es que en la mayoría de las especies ginodioicas las hembras presentan flores más pequeñas que los hermafroditas (Delph, 1996; cuadro 1). En relación con el ciclo de vida, existen tanto especies anuales como perennes, de las cuales la mayoría son de ciclo de vida corto (cuadro 1). Por último, se puede apreciar que salvo en contadas excepciones, la mayoría de las especies ginodioicas son autocompatibles (cuadro 1).

\section{Herencia de la esterilidad masculina}

Se ha propuesto que la esterilidad masculina que da lugar a las plantas hembra se podría originar de tres maneras. El caso en que el o los genes responsables de la esterilidad masculina se encuentran en el núcleo es conocido como esterilidad masculina nuclear (Lewis, 1941). Cuando los genes que afectan la producción de polen se localizan en las mitocondrias se reconoce un caso de esterilidad masculina citoplasmática (Lewis, 1941). Por último, la falta de polen viable puede ser producto de la interacción del núcleo y el citoplasma (esterilidad masculina núcleo-citoplasmática; Frank, 1989). En los dos primeros casos, las mutaciones afectan directamente la producción de polen. En la esterilidad masculina núcleo-citoplasmática los genes citoplasmáticos (mitocondriales) interrumpen la producción de polen y los nucleares son los encargados de restaurar la fertilidad masculina (Frank, 1989).

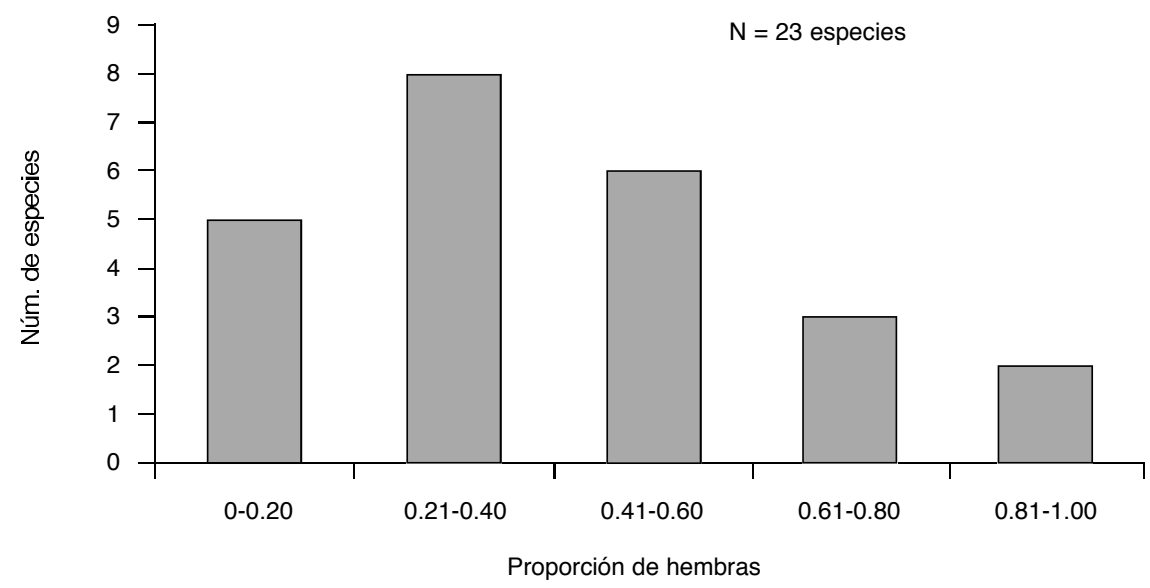

Figura 1. Variación en la frecuencia de hembras en 23 especies ginodioicas. Se presentan los valores más altos de hembras reportados para cada especie en el cuadro 1. 
Cuadro 1. Principales características de las especies ginodioicas más estudiadas. \%Hembras = ámbito de variación en el porcentaje de hembras entre distintas poblaciones. ₹ Los valores de depresión endogámica se calcularon a partir de la fórmula $\delta=1$-(Wa/We), donde Wa es la adecuación promedio de la progenie derivada de la autofecundación y We es la adecuación promedio de la progenie derivada de la entrecruza. Los valores de adecuación se obtuvieron para la germinación de las semillas, en ocasiones supervivencia de plántulas y etapa reproductiva.

* Protándrica: término que define la exposición anticipada de los granos de polen en relación a la receptividad del estigma de una flor.

+ Protogínica: término que define la receptividad anticipada del estigma en relación a la liberación del polen en una flor.

+ Sólo se conoce una población de esta especie, y por lo tanto únicamente se reporta un valor del porcentaje de hembras.

\begin{tabular}{|c|c|c|c|c|c|c|c|}
\hline Especie y Familia & $\begin{array}{l}\text { Ciclo de } \% \\
\text { vida }\end{array}$ & $\%$ Hembras & $\begin{array}{l}\text { Autocom- } \\
\text { patibilidad }\end{array}$ & $\begin{array}{l}\text { Compensación } \\
\text { reproductiva en } \\
\text { plantas hembra }\end{array}$ & $\begin{array}{l}\text { Valores estimados } \\
\text { de depresión } \\
\text { endogámica } \ddagger\end{array}$ & Observaciones & Referencia \\
\hline $\begin{array}{l}\text { Chamaecrista fasciculata } \\
\text { (Fabaceae) }\end{array}$ & Anual & $0-6$ & Sí & No & $\longrightarrow$ & $\longrightarrow$ & $\begin{array}{l}\text { Williams y Fenster } \\
\text { (1998) }\end{array}$ \\
\hline $\begin{array}{l}\text { Cucurbita foetidissima } \\
\text { (Cucurbitaceae) }\end{array}$ & Perenne & $0-32$ & Sí & $\begin{array}{l}\text { Sí, } 1.5 \text { veces } \\
\text { más semillas }\end{array}$ & 0.71 & $\begin{array}{l}\text { Las plantas } \\
\text { "hermafroditas" son } \\
\text { plantas monoicas con } \\
\text { flores unisexuales }\end{array}$ & $\begin{array}{l}\text { Kohn (1989) } \\
\text { Kohn y Biardi (1995) }\end{array}$ \\
\hline $\begin{array}{l}\text { Daphne laureola } \\
\text { (Thymelaeaceae) }\end{array}$ & Perenne & $20-56$ & Sí & No & $\begin{array}{l}\text { Infieren valores } \\
\text { altos en etapas } \\
\text { tardías del ciclo } \\
\text { de vida }\end{array}$ & $\begin{array}{l}\text { Flores pistiladas con } \\
\text { estambres vestigiales y } \\
\text { corolas más pequeñas }\end{array}$ & $\begin{array}{l}\text { Alonso y Herrera (2001) } \\
\text { Medrano et al. (2005) }\end{array}$ \\
\hline $\begin{array}{l}\text { Fragaria virginiana } \\
\text { (Rosaceae) }\end{array}$ & Perenne & $0-75$ & Sí & Sí, más frutos & 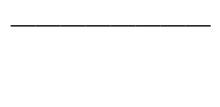 & $\begin{array}{l}\text { Herencia probablemente } \\
\text { nuclear de la esterilidad } \\
\text { masculina }\end{array}$ & Ashman (1999) \\
\hline $\begin{array}{l}\text { Geranium sy/vaticum } \\
\text { (Geraniaceae) }\end{array}$ & Perenne & $0.4-27$ & Sí & $\begin{array}{l}\text { Sí, } 1.4 \text { veces } \\
\text { más frutos }\end{array}$ & 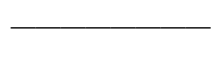 & Propagación vegetativa & $\begin{array}{l}\text { Asikainen y Mutikainen } \\
\text { (2003) }\end{array}$ \\
\hline $\begin{array}{l}\text { Gypsophila repens } \\
\text { (Caryophyllaceae) }\end{array}$ & Perenne & $14+$ & Sí & Sí, más frutos & & $\begin{array}{l}\text { Poblaciones ginodioicas } \\
\text { y ginomonoicas }\end{array}$ & $\begin{array}{l}\text { López-Villavicencio } \\
\text { et al. (2005) } \\
\text { (M. López-Villavicencio, } \\
\text { com.pers) }\end{array}$ \\
\hline $\begin{array}{l}\text { Hebe strictissima } \\
\text { (Scrophulareaceae) }\end{array}$ & Perenne & $1-34$ & Sí & $\begin{array}{l}\text { Sí, } 3 \text { veces } \\
\text { más frutos }\end{array}$ & & $\longrightarrow$ & Delph (1990) \\
\hline $\begin{array}{l}\text { Kallstroemia grandiflora } \\
\text { (Zygophyllaceae) }\end{array}$ & Anual & $0-44$ & Sí & No & - & $\begin{array}{l}\text { Dos tipos de flores } \\
\text { hembra }\end{array}$ & Cuevas et al. (2005) \\
\hline $\begin{array}{l}\text { Lobelia siphilitica } \\
\text { (Lobeliaceae o } \\
\text { Campanulaceae) }\end{array}$ & Perenne & $0-90$ & Sí & $\longrightarrow$ & 0.54 & $\begin{array}{l}\text { Protándrica *herencia } \\
\text { núcleo-citoplasmática }\end{array}$ & $\begin{array}{l}\text { Dudle et al. (2001) } \\
\text { Mutikainen et al. (1998) }\end{array}$ \\
\hline $\begin{array}{l}\text { Nemophila menziesii } \\
\text { (Hidrophyllaceae) }\end{array}$ & Anual & $0-53$ & Sí & 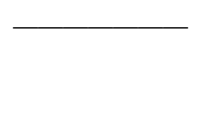 & 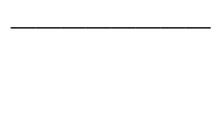 & $\begin{array}{l}\text { Protándrica, flores } \\
\text { hembra más pequeñas } \\
\text { y sin anteras }\end{array}$ & Ganders (1978) \\
\hline $\begin{array}{l}\text { Orchradenus baccatus } \\
\text { (Resedaceae) }\end{array}$ & Perenne & $23-57$ & Sí & $\begin{array}{l}\text { Sí, } 9 \text { a } 20 \text { veces } \\
\text { más semillas }\end{array}$ & & Hay individuos machos & Wolfe y Shmida (1997) \\
\hline $\begin{array}{l}\text { Origanum vulgare } \\
\text { (Labiatae o Lamiaceae) }\end{array}$ & Perenne & $1-62$ & Sí & $\begin{array}{l}1.2 \text { veces más } \\
\text { semillas }\end{array}$ & - & $\begin{array}{l}10 \text { a } 60 \% \text { de plantas } \\
\text { parcialmente estériles }\end{array}$ & Kheyr-Pour (1980) \\
\hline $\begin{array}{l}\text { Phacelia dubia } \\
\text { (Hidrophyllaceae) }\end{array}$ & Anual & $0-11$ & Sí & No & 0.7 & $\longrightarrow$ & $\begin{array}{l}\text { Del Castillo (1993), } \\
\text { (1998) }\end{array}$ \\
\hline $\begin{array}{l}\text { Phacelia linearis } \\
\text { (Hidrophyllaceae) }\end{array}$ & $\begin{array}{l}\text { Anual de } \\
\text { verano }\end{array}$ & $2-16$ & Sí & $\begin{array}{l}\text { Sí, de } 1.3 \text { a } 2.5 \\
\text { veces más frutos }\end{array}$ & & Protándrica & Eckhart (1992) \\
\hline $\begin{array}{l}\text { Plantago coronopus } \\
\text { (Plantaginaceae) }\end{array}$ & $\begin{array}{l}\text { Perenne } \\
\text { de vida corta }\end{array}$ & rta & No & $\begin{array}{l}1.5 \text { veces más } \\
\text { semillas }\end{array}$ & 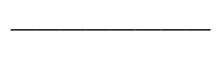 & $\begin{array}{l}\text { Dos tipos de flores } \\
\text { hembra protogínica+ }\end{array}$ & Koelewijn (1996) \\
\hline
\end{tabular}


Cuadro 1. Continua

\begin{tabular}{|c|c|c|c|c|c|c|c|}
\hline Especie y Familia & $\begin{array}{l}\text { Ciclo de } \% \\
\text { vida }\end{array}$ & $\%$ Hembras & $\begin{array}{l}\text { Autocom- } \\
\text { patibilidad }\end{array}$ & $\begin{array}{l}\text { Compensación } \\
\text { reproductiva en } \\
\text { plantas hembra }\end{array}$ & $\begin{array}{l}\text { Valores estimados } \\
\text { de depresión } \\
\text { endogámica } ¥\end{array}$ & Observaciones & Referencia \\
\hline $\begin{array}{l}\text { Plantago lanceolata } \\
\text { (Plantaginaceae) }\end{array}$ & Perenne & $4-30$ & No & Sí, más semillas & $\longrightarrow$ & $\begin{array}{l}\text { Polinización por viento, } \\
\text { herencia núcleo- } \\
\text { citoplasmática }\end{array}$ & $\begin{array}{l}\text { Van Damme y } \\
\text { Van Delden (1984) }\end{array}$ \\
\hline $\begin{array}{l}\text { Schiedea adamantis } \\
\text { (Caryophyllaceae) }\end{array}$ & Perenne & $39+$ & Sí & $\begin{array}{l}\text { Sí, } 2.3 \text { veces } \\
\text { más semillas }\end{array}$ & 0.6 & $\begin{array}{l}\text { Herencia nuclear de } \\
\text { la esterilidad masculina }\end{array}$ & Sakai et al. (1997) \\
\hline $\begin{array}{l}\text { Schiedea salicaria } \\
\text { (Caryophyllaceae) }\end{array}$ & Perenne & $12-13$ & Sí & No & 0.82 & $\begin{array}{l}\text { Herencia nuclear de la } \\
\text { esterilidad masculina }\end{array}$ & Weller y Sakai (2005) \\
\hline $\begin{array}{l}\text { Sidalcea hendersonii } \\
\text { (Malvaceae) }\end{array}$ & Perenne & $14-54$ & Sí & No & - & Especie protándrica & $\begin{array}{l}\text { Marshall y Ganders } \\
\text { (2001) }\end{array}$ \\
\hline $\begin{array}{l}\text { Sidalcea oregana } \\
\text { (Malvaceae) }\end{array}$ & Perenne & $0-50$ & Sí & $x_{1}$ & $\longrightarrow$ & Protándrica & $\begin{array}{l}\text { Ashman y Stanton } \\
\text { (1991) }\end{array}$ \\
\hline $\begin{array}{l}\text { Silene acaulis } \\
\text { (Caryophyllaceae) }\end{array}$ & Perenne & $23-25$ & Sí & $\begin{array}{l}\text { Sí, } 3 \text { veces más } \\
\text { frutos y } 2.9 \text { veces } \\
\text { más semillas }\end{array}$ & $\begin{array}{l}\text { Menor supervivencia } \\
\text { de plántulas } \\
\text { autofecundadas }\end{array}$ & Especie protándrica & Shykoff (1988) \\
\hline $\begin{array}{l}\text { Silene vulgaris } \\
\text { (Caryophyllaceae) }\end{array}$ & $\begin{array}{l}\text { Perenne de } \\
\text { vida corta }\end{array}$ & e $\quad 0-75$ & Sí & $\begin{array}{l}\text { Sí, } 1.2 \text { veces } \\
\text { más semillas }\end{array}$ & $\begin{array}{l}\text { Menor germinación } \\
\text { y supervivencia de } \\
\text { hermafroditas } \\
\text { autofecundadas }\end{array}$ & $\begin{array}{l}\text { Herencia } \\
\text { núcleo-citoplasmática }\end{array}$ & Olson et al. (2005) \\
\hline $\begin{array}{l}\text { Thymus vulgaris } \\
\text { (Labiatae o Lamiaceae) }\end{array}$ & $\begin{array}{l}\text { Perenne de } \\
\text { vida corta }\end{array}$ & $5-98$ & Sí & $\begin{array}{l}\text { Sí, hasta } 8 \text { veces } \\
\text { más semillas }\end{array}$ & 0.6 & $\begin{array}{l}\text { Las hembras no } \\
\text { presentan estambres }\end{array}$ & Domme et al. (1978) \\
\hline $\begin{array}{l}\text { Trifolium hirtum } \\
\text { (Leguminosae o } \\
\text { Fabaceae) }\end{array}$ & Anual & $0-40$ & Sí & No & 0.36 & $\begin{array}{l}\text { Diferencias sólo en } \\
\text { anteras: estériles más } \\
\text { claras y contraídas }\end{array}$ & $\begin{array}{l}\text { Molina-Freaner y } \\
\text { Jain }(1992,1993)\end{array}$ \\
\hline
\end{tabular}

De manera general, se infiere que cuando la progenie producto de las cruzas entre hembras y hermafroditas se aproxima a las proporciones mendelianas esperadas, la herencia de la esterilidad masculina es nuclear (Weller y Sakai, 1991). Dichas proporciones dependen del número de genes e interacciones entre éstos (dominancia, epistasis, etc.). Si la esterilidad masculina es citoplasmática, no hay segregación y por lo tanto una planta hermafrodita producirá únicamente hermafroditas y una planta hembra sólo hembras (Lewis, 1941). Por último, cuando la segregación de las cruzas toma cualquier valor alejándose de las predicciones mendelianas, se interpreta como herencia núcleocitoplasmática; se ha propuesto que estos resultados se deben al número de genes citoplasmáticos y nucleares involucrados en la determinación del sexo (Charlesworth y Laporte, 1998). En la actualidad, la mayoría de los estudios indican que la esterilidad masculina de origen núcleo-citoplasmático es la más común (Charlesworth y Laporte, 1998; Dudle et al., 2001). En una población ginodioica podemos tener individuos hermafroditas que no han sufrido cambio alguno, individuos estériles para la función masculina (hembras) e individuos hermafroditas restaurados (los cuales a simple vista no se pueden diferenciar de los demás hermafroditas; Murayama et al., 2004). Es decir, la expresión sexual está controlada por la interacción de varios genes que se encuentran en el núcleo y en el citoplasma. Una vez establecido el polimorfismo núcleo-citoplasmático, se ha propuesto que su dinámica dependerá de la migración o del surgimiento de alelos esterilizadores y sus respectivos restauradores (Frank, 1989). La migración o aparición de un alelo esterilizador hará que aumente la frecuencia de hembras y, por el contrario, el surgimiento o migración de un gen restaurador de la fertilidad hará que disminuya. Además, se espera que esta dinámica sea propia de cada población, por lo que es muy probable que exista heterogeneidad espacial y temporal en la frecuencia de los genes esterilizadores y restauradores y por lo tanto, en la frecuencia de hembras entre las poblaciones y especies (figura 1, cuadro 1; Frank, 1989).

\section{¿Cómo se mantienen las hembras en las poblaciones?}

En una población ginodioica, las plantas hermafroditas dejan hijos a través tanto de la vía masculina (al producir 
polen) como de la vía femenina (al producir semillas), mientras que las hembras, que son estériles para la función masculina, sólo dejan hijos a través de la vía femenina (McCauley y Brock, 1998). Un individuo que deja menos hijos se encuentra en desventaja y por ello se considera que debe existir algún mecanismo que haga que las hembras no sean eliminadas por la selección natural. Al respecto se han postulado dos hipótesis no excluyentes y ambas tienen que ver con un incremento en la cantidad y/o la calidad de las semillas de las hembras. La hipótesis de la compensación plantea que una planta hembra, al dejar de asignar recursos a la producción de polen, podría reasignar esos recursos a la vía femenina y producir un mayor número de semillas o de mejor calidad que una planta hermafrodita (Shykoff et al., 2003). Existen numerosos estudios en donde se ha documentado una mayor producción de frutos y/o semillas en las hembras de especies ginodioicas (ver revisión Shykoff et al., 2003; cuadro 1). En algunos casos como los de Silene acaulis (Shikoff, 1988) y Thymus vulgaris (Dommee et al., 1978), las hembras son capaces de producir entre tres y ocho veces más semillas, respectivamente, que los hermafroditas (cuadro 1). Sin embargo, en otros casos como en Daphne laureola (Alonso y Herrera, 2001), Sidalcea hendersonii (Marshall y Ganders, 2001) o Kallstroemia grandiflora (Cuevas et al., 2005) no se ha encontrado evidencia alguna de compensación (cuadro 1). Aunque no existe evidencia empírica, es relevante mencionar que entre más temprana sea la etapa en la que se detiene la producción de polen en las hembras, más recursos se podrían reasignar a la producción de óvulos y semillas. Por tanto, si la esterilidad masculina no se expresa igual entre las hembras, la selección natural podría favorecer a aquellas plantas en las que la esterilidad se exprese más tempranamente.

La hipótesis de la depresión por endogamia plantea que las hembras pueden aumentar su ventaja reproductiva si la progenie de los hermafroditas se ve afectada por una alta tasa de autofecundación y de depresión endogámica. Hace tiempo (Darwin, 1877) se demostró que los apareamientos entre parientes, que se conocen como endogamia biparental, y la autofecundación (endogamia uniparental, que es la forma más extrema de endogamia) pueden tener efectos negativos para las plantas. Una forma sencilla en la que se ha probado este supuesto ha sido comparando el desempeño de la progenie producto de cruzas endogámicas y no endogámicas en una misma planta. En muchas especies se ha observado que el desempeño de la progenie proveniente de las cruzas endogámicas es menor (Schemske y Lande, 1985; Husband y Schemske, 1996). Esta disminución en la adecuación debida a los apareamientos endogámicos es lo que se conoce como depresión por endogamia (Charlesworth, 1987). En el caso de las especies ginodioicas, los hijos de las hembras necesariamente son producto de fecundación cruzada, mientras que los hermafroditas pueden autofecundarse y sufrir los efectos negativos de la endogamia. Una hembra tendrá más ventaja conforme aumente la tasa de autofecundación y la depresión por endogamia en los hermafroditas (la cual se representa por $\delta$ y puede tomar valores de cero a uno). A diferencia de los numerosos estudios de compensación, en pocas especies se han evaluado el papel de la tasa de autofecundación y la depresión por endogamia, y existen aun menos especies en las que se haya explorado la compensación, la tasa de autofecundación y los niveles de depresión endogámica. El género Schiedea tiene varias especies ginodioicas y se tiene evidencia de que la depresión endogámica es un evento común (Sakai et al., 1997; Rankin et al., 2002). En el caso de Schiedea salicaria, por ejemplo, no se detectó compensación en las hembras, y sin embargo se encontró que los valores de la depresión endogámica y la tasa de autofecundación son lo suficientemente altos como para mantener las frecuencias de hembras observadas en las poblaciones (12-13\%) (Weller y Sakai, 2005). Además, debido a que la frecuencia de hembras es relativamente baja puede suponerse que la esterilidad en esta especie es un fenómeno evolutivamente reciente. Por lo tanto, es posible que cuando aparecen las hembras, éstas no presenten mecanismos compensatorios, de modo que lo que favorezca su presencia sean los altos valores de autofecundación y de depresión endogámica de los hermafroditas. Evidentemente, tanto la compensación como la depresión endogámica no son mutuamente excluyentes y ambos factores pueden favorecer la permanencia y/o el aumento en la frecuencia de hembras en una población ginodioica. Tal es el caso de Schiedea adaman tis, para la cual el coeficiente de depresión por endogamia reportado fue muy alto (0.6) y además cuyas hembras produjeron más del doble de semillas que los hermafroditas (Sakai et al., 1997). Por lo tanto, es probable que en la mayoría de las especies ginodioicas ambos mecanismos estén involucrados en el mantenimiento de las hembras, pero debido a que pocos estudios han explorado ambas hipótesis, en ocasiones parecería que la compensación es el mecanismo más frecuente.

Una excepción a la propuesta anterior es el caso del género Plantago, en el que algunas especies ginodioicas son autoincompatibles (cuadro 1), por lo que la depresión endogámica uniparental no juega un papel relevante en el mantenimiento de las hembras (Koelewijn, 1996).

\section{Modelos teóricos y mantenimiento de las hembras}

Existen diversos modelos evolutivos que han tratado de predecir los valores de compensación necesarios para la permanencia de las hembras en las poblaciones, y se ha encontrado que la magnitud de la compensación depende principalmente del tipo de herencia de la esterilidad masculina. Suponiendo que existe una herencia nuclear de la esterilidad, las hembras requieren una fertilidad del doble 
que la de los hermafroditas para poder permanecer en las poblaciones, ya que necesitan compensar la pérdida en adecuación al dejar de producir hijos por una de las dos vías (Lewis, 1941). Además, si la herencia es nuclear, el porcentaje de hembras en las poblaciones no debería ser mayor a $50 \%$, pues tanto hembras como hermafroditas producen en promedio la mitad de hembras y de hermafroditas. En cambio, bajo una herencia citoplasmática de la esterilidad, las hembras aun con una pequeña ventaja en la fertilidad no sólo pueden permanecer en las poblaciones, sino que incluso pueden alcanzar un porcentaje muy alto (debido a que una hembra produce únicamente hembras; Lewis, 1941). Posteriormente, al incorporar en los modelos nucleares los efectos de la depresión por endogamia y la autofecundación, se encontró que incluso sin la compensación, las hembras pueden permanecer en las poblaciones si la tasa de autofecundación es alta y la magnitud de la depresión por endogamia es fuerte (Charlesworth y Charlesworth, 1978; Weller y Sakai, 2005).

\section{El ginodioicismo y la evolución a la dioecia}

Se han postulado dos rutas principales a partir de las cuales se podría evolucionar a la dioecia desde una condición her- mafrodita: la vía del ginodioicismo y la del monoicismo (figura 2; aunque se han propuesto otras menos exploradas, ver Webb, 1999). En la primera vía (figura 2a) una mutación esteriliza la función masculina de algunas plantas, dando como resultado una población ginodioica (individuos hembra y hermafroditas) (Barrett, 2002). La segunda mutación tendría que ocurrir en los individuos hermafroditas y esterilizar la función femenina para tener una población dioica (figura 2a). En la segunda vía (figura 2b) se requieren al menos dos mutaciones en una misma planta herma frodita para llegar a una condición monoica (Barrett, 2002). Una mutación que afecte la producción de polen, dando lugar a las flores hembra (ginomonoicismo, Webb, 1999) y una más que afecte la función femenina de otras flores hermafroditas en la misma planta. La transición del monoicismo al dioicismo (figura $2 b$ ) puede darse por medio de cambios en la asignación de recursos que favorezcan la especialización de las funciones sexuales en cada planta y la acción de la selección diversificadora (Webb, 1999). Hasta hace algunos años se pensaba que la mayoría de las especies dioicas se habían originado por la vía del monoicismo (Renner y Ricklefs, 1995). Sin embargo, un estudio filogenético de la evolución de la dioecia en las monocotiledóneas mostró que la mayoría de los grupos

\section{Condición ancestral hermafrodita}

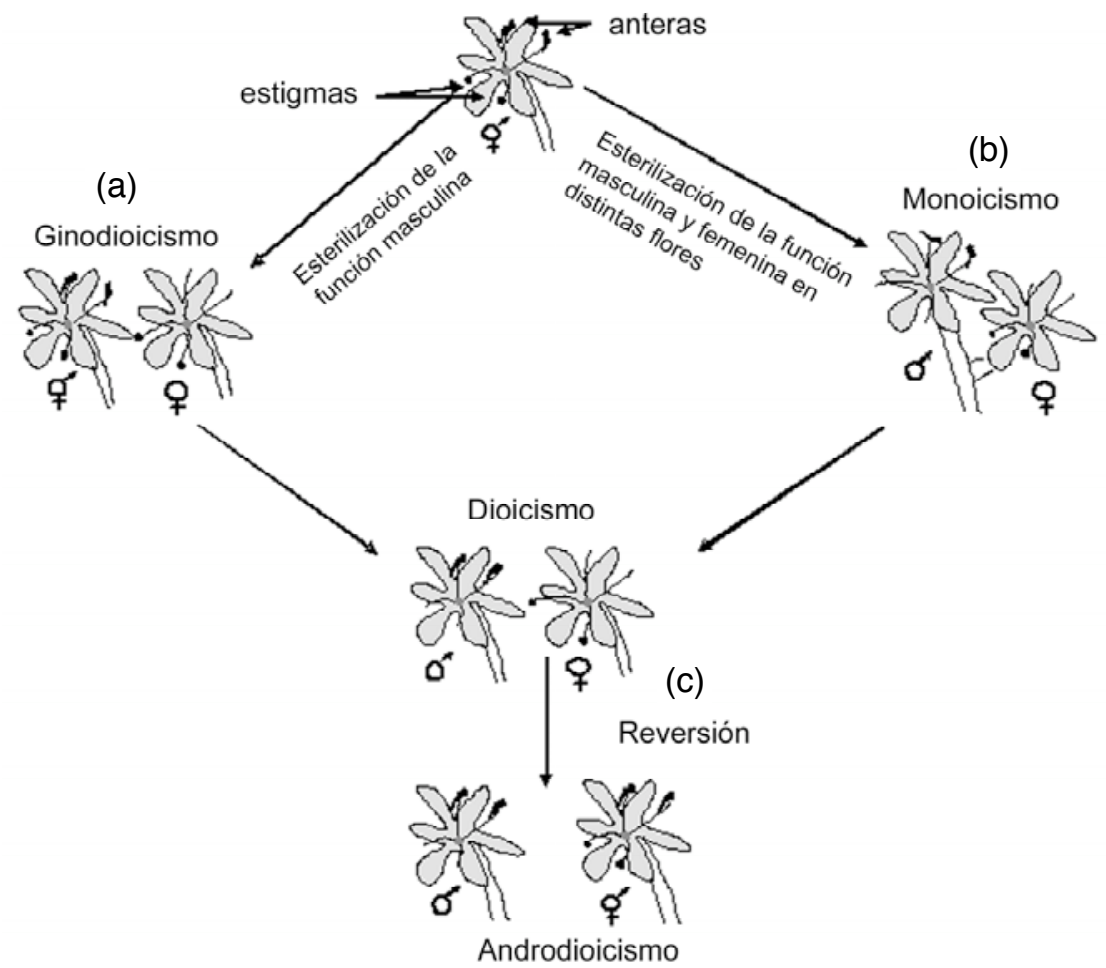

Figura 2. Principales rutas evolutivas a partir de un ancestro hermafrodita. Por ambas rutas se podría llegar a una condición dioica; sin embargo, la ruta del ginodioicismo (a) es la más explorada y con mayor evidencia empírica. (b) Vía del monoicismo y (c) reversión a partir de una condición dioica en donde las hembras restablecen la producción de polen, dando lugar al androdioicismo (presencia de plantas macho y hermafroditas). Modificado de Barrett (2002). 
hermanos de los linajes dioicos presentan flores hermafroditas y no monoicas, como se esperaría si éstos hubieran sido los ancestros (Weiblen et al., 2000). Actualmente existen pocos estudios filogenéticos que sugieren el origen de las especies dioicas a partir del monoicismo, como en el caso de la familia Siparunaceae (Renner y Won, 2001).

En cambio, uno de los argumentos que apoya la hipótesis de que el ginodioicismo es uno de los estados intermedios más probables en la evolución a la dioecia es la fuerte asociación existente entre familias que presentan especies ginodioicas y dioicas. Se sabe que de 35 familias que presentan especies ginodioicas, 89\% tiene además especies dioicas (Maurice et al., 1993). Además, existen estudios filogenéticos bien detallados como los del género Schiedea, que sugieren que las especies dioicas se originaron a partir de especies ginodioicas (Weller et al., 1995). Sin embargo, en otros casos el ginodioicismo parece ser un sistema estable, como en varias especies del género Thymus, en donde a pesar de la alta frecuencia de hembras en algunas especies (cuadro 1), no se conoce ninguna población o especie dioica. Por ello, al referirnos a las especies ginodioicas, no podemos verlas como especies que se encuentran en un estado evolutivo transitorio hacia la dioecia. Por otro lado, un hecho que llama la atención es que entre las especies ginodioicas existan tanto especies de ciclo de vida anual como perenne (cuadro 1), mientras que la gran mayoría de las especias dioicas son perennes. Por lo tanto, es probable que exista alguna restricción en el caso de las especies ginodioicas anuales para evolucionar hacia la dioecia, o si este evento ha ocurrido, al parecer no ha sido exitoso, ya que en la actualidad se conocen muy pocos ejemplos. Un dato que podría apoyar parcialmente esta hipótesis es la alta tasa de extinción en especies dioicas en general (Helibuth, 2000), pues cabe la posibilidad de que muchas de las especies extintas fueran anuales.

Finalmente, es posible que las hembras de especies dioicas recobren la producción de polen dando lugar al androdioicismo, situación en la que coexisten plantas macho y hermafroditas (figura 2c). Hasta hace algunos años se pensaba que las especies androdioicas se originaban a partir de especies hermafroditas de una manera similar a como se origina el ginodioicismo, pero a través de la esterilización de la función femenina de los hermafroditas. El androdioicismo es una situación muy poco frecuente en la naturaleza y se ha reportado en alrededor de 10 especies (Panell, 2002). Esto se debe a que la autofecundación de los hermafroditas disminuye el éxito de los machos, ya que pierden oportunidades de aparearse (Sato, 2002). Además, se ha estimado que los machos, para poder permanecer en las poblaciones, requieren producir más del doble de polen que los hermafroditas (Panell, 2002) y exportarlo exitosamente (Fritsch y Rieseberg, 1992).

Por otra parte, teóricamente es posible proponer que un sistema reproductivo que promueve una estrategia reproductiva mixta como el ginodioicismo, en donde una proporción de la progenie en una población es producto de fecundación cruzada y otra de autofecundación, tendría más ventajas que una población en donde los individuos se entrecruzan o se autofecundan predominantemente. Por lo tanto, si el ginodioicismo tiene esas ventajas, ¿por qué se conocen tan pocas especies ginodioicas? y ¿qué condiciones podrían favorecer su evolución a la dioecia? Para tratar de responder a la primera pregunta, debemos tener en cuenta que en muchas ocasiones la esterilidad masculina no es evidente y se requiere de estudios embriológicos detallados (Domínguez et al., 1997), por lo que en la actualidad seguimos conociendo nuevas especies ginodioicas (Cuevas et al., 2005). Por otro lado, aunque en muchas especies hermafroditas surjan las mutaciones que den origen a poblaciones ginodioicas, las hembras serán eliminadas si no presentan una ventaja reproductiva. Otra posibilidad es que un restaurador de la fertilidad se fije en una población, restituyendo así la fertilidad de todas las hembras, y de no surgir otro esterilizador, no podríamos detectar en ese momento que se trata de la dinámica núcleo-citoplasmática del ginodioicismo (Maniacacci et al., 1996). Para responder a la segunda pregunta debemos recordar que en la mayoría de las angiospermas las mitocondrias se heredan por la vía materna, es decir, a través de los óvulos. Por lo tanto, cualquier mutación mitocondrial que afecte la producción de polen será favorecida si los recursos que se asignaban a producir polen y óvulos ahora sólo se asignan para producir óvulos, aumentando el número de genes citoplasmáticos en cada generación (Hurst, 1996). Sin embargo, los genes nucleares se heredan biparentalmente; es decir, están representados tanto en los óvulos como en el polen. De esta forma, al detenerse la producción de polen, bajaría la adecuación de algunos genes nucleares, los cuales serían transmitidos únicamente en los óvulos. Así, el control núcleocitoplasmático del sexo, presente en la mayoría de las especies ginodioicas, puede originar conflictos de carácter genético entre el núcleo y las mitocondrias y la separación de los sexos resolvería esos conflictos, pues tanto el polen como los óvulos se producirían en diferentes individuos (Hurst, 1996).

El hecho de que en muchas especies ginodioicas la esterilidad masculina esté determinada de una manera núcleo-citoplasmática ha modificado las predicciones evolutivas y los mecanismos por los cuales se puede evolucionar hacia la dioecia (Maurice et al., 1994). Por un lado, en los modelos teóricos se ha encontrado que la herencia núcleo-citoplasmática de la esterilidad masculina presenta situaciones menos restrictivas para la evolución hacia la dioecia. Por otro lado, debido a que en la mayoría de las especies dioicas la determinación sexual está controlada nuclearmente, es necesario proponer nuevos mecanismos por los que se podría pasar de una herencia núcleo-citoplas- 
mática a un control nuclear (como la migración de genes citoplasmáticos al núcleo y su posterior control nuclear en la expresión de estos genes).

\section{Comentarios finales}

Como se puede apreciar en esta revisión, un hecho aparentemente sencillo como la presencia de las hembras en las poblaciones hermafroditas, puede tener implicaciones relevantes en el ámbito ecológico y evolutivo. Probablemente esto ha motivado la creciente detección de este polimorfismo y por ello actualmente existen cada vez más reportes de especies ginodioicas en el mundo. En México contamos con una gran riqueza de plantas con flor (entre 26,000 y 30,000 especies; González-Medrano, 2003). Sin embargo, hasta ahora existen muy pocos reportes y aun menos estudios con especies ginodioicas. Bullock (1985), en lo que es la clasificación más extensa de sistemas reproductivos para la reserva de Chamela, Jalisco, encontró que de 708 especies estudiadas, cuatro presentaron un sistema ginodioico. Además, existen reportes aislados como el de Bursera fagaroides que en Sonora presenta al menos una población ginodioica (F. Molina-Freaner, com.pers.), o el de Kallstroemia grandiflora, en la que la mayoría de las poblaciones son ginodioicas (Cuevas et al., 2005). Debido al gran potencial que nos brindan los sistemas reproductivos, pensamos que es necesario que los botánicos y ecólogos presten mayor atención a la determinación y estudio de los sistemas reproductivos de las plantas. Si bien en ocasiones la determinación de los sistemas reproductivos requiere de observaciones detalladas en el campo, este esfuerzo bien vale la pena, ya que indudablemente se trata de un tema fascinante de estudio.

\section{Agradecimientos}

Queremos expresar nuestro sincero agradecimiento a nuestros compañeros de laboratorio, especialmente a Fe rnando Rosas y Jéssica Pérez, quienes enriquecieron este trabajo a través de va rios seminarios. Raúl Alcalá, Juan A rroyo, Amadeo Estrada, Celia Oliver y tres revisores anónimos leye ron y mejora ron con sus comentarios versiones previas. Agradecemos a CONACyT por las becas de doctorado recibidas durante la realización de este trabajo.

\section{Literatura citada}

Alonso C. y Herrera C. 2001. Neither vegetative nor reproductive advantages account for high frequencies of male steriles in southern Spanish gynodioecious Daphne laureola. American Journal of Botany 88:1016-1024.

Ashman T.L. 1999. Determinants of sex allocation in a gynodioecious wild strawberry: implications for the evolution of dioecy and sexual dimorphism. Journal of Exolutionary Biology 12:648-661.
Ashman T.L. y Stanton M. 1991. Seasonal variation in pollination dynamics of sexually dimorphic Sidalcea oregana (Malvaceae). Ecology 72:993-1003.

Asikainen E. y Mutikainen P. 2003. Female frequency and relative fitness of females and hermaphrodites in gynodioecious Geranium sylvaticum (Geraniaceae). American Journal of Botany 90:226-234.

Barrett S. 2002. The evolution of plant sexual diversity. Nature Reviews 3:274-284.

Barrett S. y Eckert J. 1990. Variation and evolution of mating systems in seed plants. En: Kawano D. Ed. Biological Approaches and Evolutionary Trends in Plants, pp. 57-71, Academic Press, NuevaYork.

Bullock H.S. 1985. Breeding systems in the flora of a tropical deciduous forest in México. Biotropica 17:287-301.

Charlesworth B. y Charlesworth D. 1978. A model for the evolution of dioecy and gynodioecy. American Naturalist 112:975997.

Charlesworth D. y Charlesworth B. 1987. Inbreeding depression and its evolutionary consequences. Annual Review of Ecology and Systematics 18:237-268.

Charlesworth D. y Laporte V. 1998. The male-sterility polymorphism of Silene vulgaris: analysis of genetic data from two populations and comparison with Thymus vulgaris. Genetics 150: $1267-1282$.

Collin C.L. y Shykoff J. 2003. Outcrossing rates in the gynomonoecious-gynodioecious species Dianthus silvestris (Cariophyllaceae). American Journal of Botany 90:579-585.

Cuevas E., Márquez-Guzmán J., Domínguez C.A. y MolinaFreaner F. 2005. Evidence of gynodioecy in Kallstroemia grandiflora (Zygophyllaceae): microsporogenesis in hermaphrodite and female plants and lack of reproductive compensation. International Journal of Plant Sciences 166:481-491.

Darwin C. 1859. On the Origin of Species by Means of Natural Selection or the Preservation of Favored Races in the Struggle for Life. John Murray, Londres.

Darwin C. 1877. The Different Forms of Flowers on Plants of the Same Species. John Murray, Londres.

Del Castillo R. 1993. Consequences of male sterility in Phacelia dubia. Evolutionary Trends in Plants 7:5-22.

Del Castillo R. 1998. Fitness consequences of maternal and nonmatemal components of inbreeding in the gynodioecious Phacelia dubia. Evolution 52:44-60.

Delph L.F. 1990. Sex ratio variation in the gynodioecious shrub Hebe strictissima (Scrophulariaceae). Evolution 44:134-142.

Delph L.F. 1996. Sexual dimorphism in life history. En: Geber M., Dawson T. y Delph L.F. Eds. Gender and Sexual Dimorphism in Flowering Plants, pp. 149-169, Springer Verlag, Berlín.

Dem'yanova A.E. 1985. Distribution of gynodioecy in flowering plants. Botanicheskii Zhurnal 70:1289-1301.

Dommee B., Assoaud W. y Valderyon G. 1978. Natural selection and gynodioecy in Thymus vulgaris. Botanical Journal of the Linnean Society 77:17-28.

Domínguez C.A., Ávila-Sakar G., Vázquez-Santana S. y Márquez-Guzmán J. 1997. Morph-biased male sterility in the tropical distylous shrub Erythroxylum havanense (Erythroxylaceae). American Journal of Botany 84:626-632.

Dudle D., Mutikainen P. y Delph L.F. 2001. Genetics of sex determination in the gynodioecyous species Lobelia siphilitica: evi- 
dence from two populations. Heredity 86:265-276.

Eckart V. 1992. The genetics of gender and the effects of gender on floral characters in gynodioecious Phacelia linearis (Hydrophyllaceae). American Journal of Botany 79:792-800.

Fleming T., Maurice S. y Hamrick J. 1998. Geographic variation in the breeding system and the evolutionary stability of trioecy in the Pachycereus pringlei (Cactaceae). Evolutionary Ecology 12:279-289.

Frank S.A. 1989. The evolutionary dynamics of cytoplasmic male sterility. American Naturalist 133:345-376.

Fritsch P. y Rieseberg L. 1992. High outcrossing rates maintain male and hermaphrodite individuals in populations of the flowering plant Datisca glomerata. Nature 359:633-636.

Frohlich M. 2003. An evolutionary scenario for the origin of flowers. Nature Reviews 4:559-566.

Futuyma D.J. 1998. Evolutionary Biology. Sinauer, Sunderland.

Ganders F. 1978. The genetics and evolution of gynodioecy in Nemophila menziesii (Hydrophyllaceae). Canadian Journal of Botany 56:1400-1408.

González-Medrano F. 2003. Las Comunidades Vegetales de México. Instituto Nacional de Ecología, SEMARNAT, México, D.F.

Helibuth J. 2000. Lower species richness in dioecious clades. American Naturalist 156:221-241.

Hurst L. 1996. Genetic Conflics. The Quarterly Review of Biology 71:317-364.

Husband B. y Schemske D. 1996. Evolution of the magnitude and timing of inbreeding depression in plants. Evolution 50:54-70.

Kaul M.L.H. 1988. Male Sterility in Higher Plants. SpringerVerlag, Berlín.

Kheyr-Pour A. 1980. Nucleo-cytoplasmic polymorphism for male sterility in Origanum vulgare L. Heredity 71:1500-1503.

Koelewijn H. 1996. Sexual differences in reproductive characters in gynodioecious Plantago coronopus. Oikos 75:443-452.

Kohn J. 1989. Sex ratio, seed production, biomass allocation and the cost of male function in Cucurbita foetidissima (Cucurbitaceae). Evolution 43:1424-1434.

Kohn J. y Biardi J. 1995. Outcrossing rates and inferred levels of inbreeding depression in gynodioecious Cucurbita foetidissi ma (Cucurbitaceae). Heredity 75:77-83.

Lewis D. 1941. Male sterility in natural populations of hermaphrodite plants. New Phytologist 40:56-63.

López-Villavicencio M., Genton B., Porcher E. y Shykoff A. 2005. The role of pollination level on the reproduction of females and hermaphrodites in the gynodioecious plant Gypsophila repens (Caryophyllaceae). American Journal of Botany 92:1995-2002.

Manicacci D., Couvet D., Belhassen E., Gouyon P.H. y Atlan A. 1996. Founder effects and sex ratio in the gynodioecious Thymus vulgaris L. Molecular Ecology 5:63-72.

Marshall M. y Ganders F. 2001. Sex-biased seed predation and the maintenance of females in a gynodioecious plant. American Journal of Botany 88:1437-1443.

Maurice S., Belhassen E., Couvet D. y Gouyon P. 1994. Evolution of dioecy: can nuclear-cytoplasmic interactions select for maleness? Heredity 73:346-354.

Maurice S., Charlesworth D., Desfeux C., Couvet D. y Gouyon D. 1993. The evolution of gender in hermaphrodites of gynodioecious populations with nucleo-cytoplamatic male-sterility. Proccedings of the Royal Society of London (Series B)
34:253-261.

McCauley D. y Brock M. 1998. Frequency-dependent fitness in Silene vulgaris, a gynodioecious plant. Evolution 52:30-36.

Medrano M., Alonso C. y Herrera C. 2005. Mating system, s ex ratio, and the persistence of females in the gynodioecious shrub Daphne laureola L. (Thymelaeaceae). Heredity 94:37-43.

Molina-Freaner F. y Jain S. 1992. Female frequencies and fitness components between sex phenotypes among gynodioecious populations of the colonizing species Trifolium hirtum All. in California. Oecologia 92:279-286.

Molina-Freaner F. y Jain S. 1993. Inbreeding effects in a gynodioecious population of the colonizing species Trifolium hirtum All. Evolution 47:1472-1479.

Murayama K., Yahara T. y Terachi T. 2004. Variation of female frequency and cytoplasmic male-sterility gene frequency among natural gynodioecious populations of wild radish (Raphanus sativus L.). Molecular Ecology 13:2459-2464.

Mutikainen P. y Delph L.F. 1998. Inbreeding depression in gynodioecious Lobelia sphilitica: among-family differences override between-morph differences. Evolution 52:1572-1582.

Olson M., McCauley D. y Taylor D. 2005. Genetics and adaptation in structured populations: sex ratio evolution in Silene vul garis. Genetica 123:49-62.

Pannell J. 2002. The evolution and maintenance of androdioecy. Annual Review of Ecology and Systematics 33:397-425.

Rankin A.E., Weller S. y Sakai A. 2002. Mating system instability in Schiedea menziesii. (Caryophyllaceae). Evolution 56:1574-1585.

Renner S. y Ricklefs R.E. 1995. Dioecy and its correlates in the flowering plants. American Journal of Botany 82:596-606.

Renner S. y Won H.S. 2001. Repeated evolution of dioecy from monoecy in Siparunaceae (Laurales). Systematic Biology 50:700-710.

Richards A. 1986. Plant Breeding Systems. Cambridge University Press, Cambridge.

Sakai A. y Weller S. 1999. A review of terminology, biogeographic patterns, ecological correlates, and phylogenetic approaches. En: Geber M., Dawson T. y Delph L.F. Eds. Gender and Sexual Dimorphism in Flowering Plants, pp. 1-25, Springer Verlag, Berlín.

Sakai A., Weller S., Chen M., Cou S. y Tasanont C. 1997. Evolution of gynodioecy and maintenance of females: The role of inbreeding depression, outcrossing rates, and resource allocation in Schiedea adamantis (Caryophyllaceae). Evolution 51:724-736.

Sato H. 2002. Invasion of unisexual in hermaphrodite populations of animal-pollinated plants: effects of pollination ecology and floral size-number trade-offs. Evolution 56:2374-2382.

Schemske D. y Bradshaw H. 1999. Pollinator preference and the evolution of floral traits in monkeyflowers (Mimulus). Proccedings of the National Academy of Science USA 12:11910-11915.

Schemske D. y Lande R. 1985. The evolution of self-fertilization and inbreeding depression in plants. II. Empirical observations. Evolution 39:41-52.

Shykoff J. 1988. Maintenance of gynodioecy in Silene acaulis (Caryophyllaceae): stage specific fecundity and viability selection. American Journal of Botany 75:844-850.

Shykoff J., Kolokotronis S., Collin C.L. y López-Villavicencio M. 
2003. Effects of male sterility on reproductive traits in gynodioecious plants: a meta-analysis. Oecologia 135:1-9.

Sun M. 1999. Cleistogamy in Scutellaria indica (Labiatae): effective mating system and population genetic structure. Molecular Ecology 8:1285-1295.

Van Damme J.M.M. y Van Delden W. 1984. Gynodioecy in Plantago lanceolada L. IV. Fitness components of sex types in different life cycle stages. Evolution 38:1326-1336.

Webb C. 1999. Empirical studies: Evolution and maintenance of dimorphic breeding systems. En: Geber M., Dawson T. y Delph L.F. Eds. Gender and Sexual Dimorphism in Flowering Plants, pp. 61-96, Springer Verlag, Berlín.

Weiblen G.D., Oyama R.K y Donoghue M.J. 2000. Phylogenetic analysis of dioecy in monocotyledons. American Naturalist 155:45-58.

Weller S.G. y Sakai A. 1991. The genetic basis of male sterility in
Schiedea (Caryophyllaceae), an endemic Hawaiian genus. Heredity 67:265-273.

Weller S.G. y Sakai A. 2005. Selfing and resource allocation in Schiedea salicaria (Caryophyllaceae), a gynodioecious species. Journal of Evolutionary Biology 18:301-308.

Weller S.G., Wagner W. y Sakai A. 1995. A phylogenetic analysis on Schiedea and Alsinidendron (Caryophyllacea: Alsinoidea): implications for the evolution of breeding systems. Systematic Botany 20:315-337.

Williams H. y Fenster C. 1998. Ecological and genetic factors contributing to the low frequency of male sterility in Chamaecrista fasciculata (Fabaceae). American Journal of Botany 85:1243-1250.

Wolfe L. y Sumida A. 1997. The ecology of sex expression in a gynodioecious Israely desert shrub (Ochradenus baccatus). Ecology 78:101-110.

Fecha de recepción: 24 de junio de 2005

Versión corregida: 27 de febrero de 2006

Aceptado: 27 de febrero de 2006 